\title{
THE FORETIETH ANNIVERSARY OF EVENT ONE AT THE ROYAL COLLEGE OF ART
}

Catherine Mason

7 Marchmont Road

Richmond Surrey

UK

catherine.mason@dsl.pipex.com

http://www.catherinemason.co.uk

\begin{abstract}
Event One was the first major public activity of the Computer Arts Society (CAS) founded in 1969 "to promote the creative use of computers in the arts". Now celebrating its fortieth year, this paper will examine the concepts behind the aims and objectives of CAS through this exhibition staged in March 1969 at the Royal College of Art. Participants from the realms of fine art and computer programming, among others offered a range of visitor experiences from graphics to live performance. Event One heralded the collaborative, cross-disciplinary nature of working which came to signify the early period of media arts.
\end{abstract}

\section{INTRODUCTION}

As its name suggests, Event One was the first exhibition of the Computer Arts Society (CAS). Conceived in 1968 and officially founded in 1969, CAS was the first practitioner-led organisation in Britain created "to promote the creative use of computers in the arts, and to encourage the interchange of information in this area" [1]. Now celebrating its fortieth year, this paper will examine the concepts behind the aims and objectives of this society through its first major public activity - Event One. Staged in March 1969 at the Royal College of Art, London (RCA) this event included participants from the realms of architecture, fine art, computer programing and filmmaking, among others and offered a range of visitor experiences from sculpture and graphics to live performance and workshops. Event One heralded the collaborative, cross-disciplinary nature of working which came to signify the early period of media arts in Britain, where interactivity and process were as equally valued as object.

This paper draws on archive materials from the Computer Arts Society, a number of press articles as well as unpublished papers and interviews with related individuals collated from 2002 to 2005 during the author's period as a researcher and student with the CACHe Project (Computer Arts, Contexts, Histories etc.) at Birkbeck, University of London funded by the Arts and Humanities Research Council [2]. The three major published references to Event One are the 23 page catalogue, the first issue of CAS's journal PAGE and two articles in Studio International. BBC film footage of 26 March 1969 has also been located and viewed. No references to Event One could be found at the RCA library and archive. Specifically for this paper, a number of people involved in Event One have been traced and interviewed, although it has proven impossible to trace all participants. 


\section{THE COMPUTER ARTS SOCIETY}

Conceived in the optimistic cultural climate surrounding Cybernetic Serendipity, CAS was founded in 1969 and became the major group active during this period. Its exhibitions, workshops and journal reached many of the pioneers of British computer arts. Funded by the British Computer Society, CAS was able to support pioneers by acting as an international forum for the exchange of ideas between people and by bringing them together for conferences, exhibitions and monthly meetings.

Although historically artist-led groups have operated mainly outside the mainstream art world, the history of modernism has largely been constructed through the identification of series of avant-garde groups of artists. It is these groups that are later defined and categorised to become movements and thus enter the canon of art history, the French Impressionists being one among many examples. In the 1970s artist-led groups were an integral part of the development of computer arts in the UK and point to the unique nature of this type of art. These artist-led initiatives were able to address the challenge of exhibition and dissemination of work in a field that was not necessarily readily accepted or understood by the public or mainstream art world at the time. CAS allowed social contact and networking opportunities, provided encouragement, inspiration, support of a technical and occasionally financial nature and perhaps most crucially access to expertise and equipment, as the group contained participants from technical and/or scientific backgrounds.

The three main founders of CAS, Alan Sutcliffe, George Mallen and R John Lansdown, had been involved with computing and its related concepts for some time. They all participated in or advised on Cybernetic Serendipity (2 August - 20 October 1968) at the Institute of Contemporary Arts, London. One of the major features of early computer arts is that it can involve people from a non-art background and Cybernetic Serendipity made this explicit. The breaking down of barriers between disciplines was an important factor evident in this exhibition. Machines were shown alongside artworks and no differentiation was made between object, process, material or method, nor between the backgrounds of makers, whether art school educated or not. One of the aims of Cybernetic Serendipity was to show the scope of what was possible, emphasising the optimistic and celebratory nature of the project. Sutcliffe, a programmer at International Computers Limited (ICL), was involved with Cybernetic Serendipity through his collaboration with composer Peter Zinovieff and Electronic Music Studios (EMS). Mallen worked with the cybernetician Gordon Pask at Systems Research and assisted on the production of the interactive robotic work Colloquy of Mobiles shown at the exhibition. The curator Jasia Reichardt knew and respected Lansdown who, from 1963, had used early CAD techniques in architectural design and planning.

The original idea for a society dedicated the computer arts (which was to become CAS) was instigated by Sutcliffe at the IFIP (International Federation for Information Processing) Congress in August 1968 in Edinburgh. Names of interested individuals were collected and the group named CAS with 'Arts' in the plural to indicate its inclusive nature. Now individuals started to see themselves as part of a larger movement - sharing an interest in the power of new technologies and what this could mean for the 
arts. It was recognised that this was an area where there had been increasing activity, but with little formal publication of methods and results and little communication between artists in different fields (music, visual, performing arts, and so on). CAS and the various activities of its members demonstrate that, from the beginning, they understood that computing innovations would fundamentally affect humanity. One of CAS's stated aims was to provide "a forum in which artists and scientists [could] jointly work out these implications" [3]. This was achieved through events and exhibitions, monthly meetings and publication of a bulletin named $P A G E$, which commenced in the wake of Event One in April 1969 and ran until 1985 [4]. The first editor was Gustav Metzger, who named the journal, thereby establishing from the beginning an association with the avant-garde. As early as 1961, Metzger had stated in his manifestos that "...the artist may collaborate with scientists, engineers" and described ways of working creatively with computing technology [5]. The journal's name was a pun on the concept of paging (the use of disk memory as a virtual store which had been introduced on the Ferranti Atlas Computer) and the fact that there was only one page available for printing the new bulletin (due to costs). PAGE featured the work of major British and international computer artists as well as hosting fundamental discussions as to the aims and nature of computer art. $P A G E$, and indeed CAS generally, embraced an inclusive policy anything, within reason, that was submitted was included. Additionally collaborations with artists outside the group were sought from time to time. Malcolm Le Grice (at this time a painter and tutor at St Martins School of Art) joined CAS early on as it "promised practical collaboration with professionals in that technology" [6]. Dominic Boreham, a later editor of PAGE, described CAS as "like an iceberg, only a small portion of it was visible. Within the membership there was a great deal of expertise, knowledge, talent, history, etc., and the Society was an important node of contact for a very dispersed international membership" [7]. By 1971 there were 377 individual and institutional members in 17 countries and branches operating in Holland and the United States.

\section{EVENT ONE}

CAS's inaugural exhibition was Event One staged in the Gulbenkian Hall of the Royal College of Art over the weekend 29 to 30 March 1969. Described as "well planned, well equipped with hardware and well attended" [8], it attracted 700 visitors. From surviving feedback questionnaires it can be seen that there was a equal balance of male and female participants from young to retired from a variety of professions including students. A PDP-7 computer with visual display unit was borrowed from Imperial College (and used to give demonstrations of the light-pen and other CAD applications), teletype terminals plus graph plotters came from commercial companies Time Sharing Limited and GEIS. A telephone link to Zinovieff's PDP-8 was established with a VDU supplied by ICL. According to Metzger the combination of fine art with working equipment was nothing less than a "revolution in the British art world" and represented "the major collective step forward" [9]. Event One was interdisciplinary, incorporating architecture, sculpture, theatre, graphics, music, poetry, film, performance and dance. As a collaboration of artists and programmers, it was to forecast the future 
activities of CAS. The exhibition was experimental, optimistic and particularly strong on performance-based work. The intention was to create the atmosphere of a workshop rather than an exhibition and to describe the type of "open-ended research necessary for working with computers and other new media" [10]. Indeed one of the early stated aims of CAS was the establishment of a permanent workshop where artists could cooperate with computer experts. (This was partially fulfilled by John Lifton's IRAT initiative.)

The name of the show was chosen by chosen by Sutcliffe. The Royal College of Art was chosen as a venue because a number of CAS committee members had associations there. This included the architect Ian Pickering who was teaching there. In addition Lansdown knew Patrick Purcell, an advocate of interdisciplinary work at the RCA since 1964, who had made grant applications to a Science Research Council panel chaired by Lansdown. Purcell persuaded Professor Bill Elliott at Imperial to loan the PDP-7 [11]. It was deemed important by the committee to have a full programme of activity throughout the weekend in order that visitors arriving at any point would be able to see a variety of performances, demonstrations and so on. Indeed Metzger reported in $P A G E$ 1 that it was the "mobility of sound and people [which] added to the excitement and sense of integration". Pickering wrote in the catalogue that he was "simultaneously bewildered and exhilarated by the potential effect of computers on the whole of society" [12], echoing both the sense of optimism and awe at being in at the beginning of something life-changing felt by many present. Artists and programmers collaborated and, for some, such collaborations had profound results. Due to space limitations it is impossible to describe all exhibits here; a selection is provided to indicate the crossdisciplinary nature of the undertaking and the variety.

Filmmaker Malcolm Le Grice collaborated with Sutcliffe on a performance work entitled Typodrama. Together they wrote a program that generated instructions and dialogue for performing actors. Le Grice wrote, “... the fragmented abstraction, caused in large measure by the invention from scratch of a "dialogue-engine", was not only "true" to the condition of computer art at the time, but matched contemporaneous artistic concerns breaking traditional hierarchies"[13]. The aesthetic concerns related to some of his films of the time, which used found footage and a cut-up style, incorporating performance, which remains an important part of his work to date. The collaboration with Sutcliffe inspired Le Grice to learn FORTRAN programming, which he was to use later in the year during a Science Research Council-funded residency at the Atlas Laboratory (1969-70).

Sutcliffe himself contributed Likeness, a version of his computer-generated poem $S P A S M O$, which was originally written for a concert of electronic music at the Queen Elizabeth Hall in February 1969, using the ICL 1904 computer and a line-printer. Copies of this poem were inserted into the Event One catalogue. The poem was also translated into Serbo-Croate and sent to the New Tendencies 4 symposium at Zagreb (May-August 1969).

Another collaboration took place between Metzger and Beverly Rowe from the University of London Computing Centre, who acted as a consultant to Metzger. In the catalogue Rowe states he is "interested in the whole problem of applying computers to 


\section{EVA 2009 London Conference 6-8 July \\ Catherine Mason}

the arts and the social implications". Metzger's 1961 manifesto declared his interest in computer controlled cybernetic systems, "The immediate objective is the creation, with the aid of computers, of works of art whose movements are programmed and include 'self-regulation"'. Metzger's 'biggest project ever proposed', Five Screens with Computer, was still being finalised in 1968 and therefore too late to be included in Cybernetic Serendipity, but did appear in the accompanying publication with an illustration. A metal model for this work was subsequently exhibited at Event One. Consisting of five frames $40 \mathrm{ft}$ long, $30 \mathrm{ft}$ high and $2 \mathrm{ft}$ deep spaced $30 \mathrm{ft}$ apart, its operation was described in detail in the catalogue. Due to the massive scale and prohibitive cost, this project is as yet unrealised. However Metzger's ideas had an impact on those of his peers. Recently Sutcliffe commented that Metzger's interests in "Generative procedures, self-regulation and interaction became key concerns in the early years of the CAS and remain so today" [14].

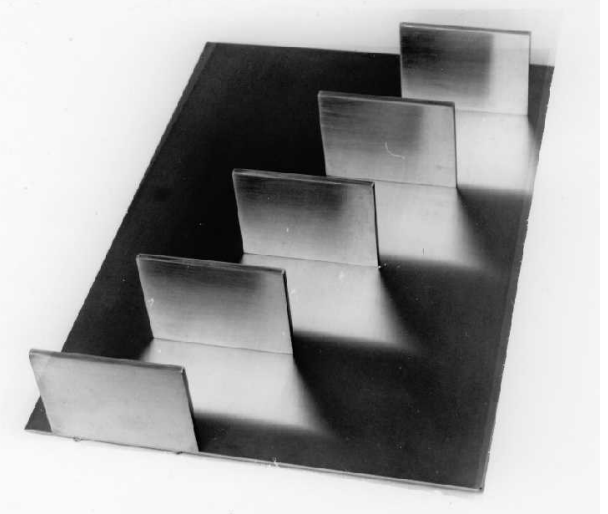

Figure 1. Gustav Metzger, Model for Five Screens with Computer (computercontrolled Auto-Destructive Monument), metal, 1969. Collection Generali Foundation, Vienna. Photograph $\odot$ Alan Sutcliffe

R John Lansdown was interested in computer-generated choreography and held what appears to be the first public performance of the Theatrical Sword Fight. Movements and instructions for two professional actors were generated such as 'thrust', 'cut to' and so on with a series of and/or instructions designed, as Lansdown wrote, "to allow free flowing movements but, at the same time preventing impossible or dangerous play". He saw computer art as a specialised form of artificial intelligence and believed that the creative use of computers could "simulate and study human intelligence [and] widen the scope of artistic creativity" [15]. Another performance by Lansdown was Word Generator Program which had references to concrete poetry. He also contributed Trilogy a dance/performance work in three pieces based on computer-generated mime scripts. The program was devised in conjunction with George Mallen and John Lifton and was performed to a backdrop of a live light and sound system built and programmed by Lifton. Three days before Event One opened a team from BBC television's Tomorrow's World filmed the Sword Fight and dancers from the Royal College Ballet School performing to Lansdown's computer-generated Benesh notations 


\section{EVA 2009 London Conference 6-8 July \\ Catherine Mason}

(screened 26/03/69). The artist and his dancers appeared in the Daily Mirror newspaper, seen here $(24 / 03 / 69)$.

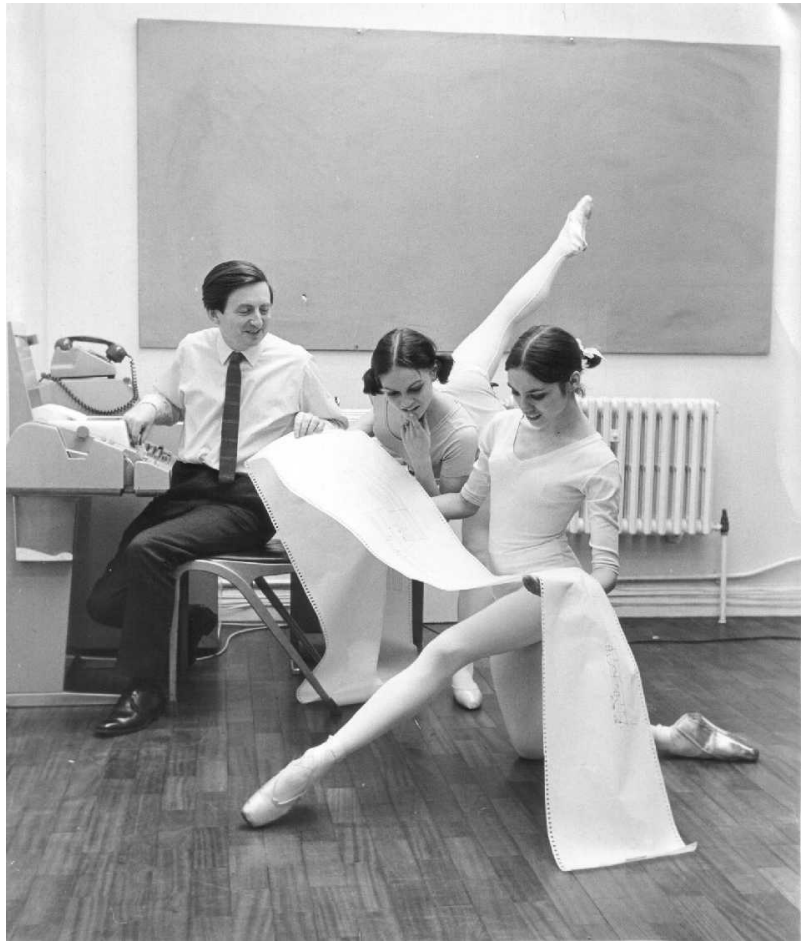

Figure 2. Photograph of R John Lansdown with dancers from the Royal Ballet School rehearsing computer-generated dance notation, 1969

John Lifton, an architect trained at the Bartlett School of Architecture at University College London, had an interest in cybernetics and synaesthetic environments and was an exhibitor at Cybernetic Serendipity. He believed that computers offered ways of transferring information from expression in one medium to another and thereby synthesizing separate sense perceptions into one experience. He further believed such systems driven by computing technologies could be engines for social change. The ultimate result would be, "an interaction between man and environment in which they become fused into one extended system" [16]. In 1969 Lifton was one of the founders of The Institute for Research in Art and Technology (IRAT). IRAT became known colloquially as the New Arts Lab and housed a theatre, gallery and cinema plus various eclectic groups. The concept of a laboratory applied to experimental art had parallels with the E.A.T organisation in New York and was appealing for many British pioneers. At IRAT Lifton ran the 'Electronics and Cybernetics workshop', which included the first computer terminal in the UK offering what he described as, "free and exclusive access for artists" with an ASR30 Teletype, operating on an off-peak telephone service [17].

A number of exhibitors produced works involving light and sound based on cybernetic systems. Philip Hodgetts' light sound structure, seen below, was a threedimensional cubic lattice of light bulbs selectively illuminated in a programmed 


\section{EVA 2009 London Conference 6-8 July \\ Catherine Mason}

sequence. It also generated sound, the rhythm and speed affected by the ambient light level.

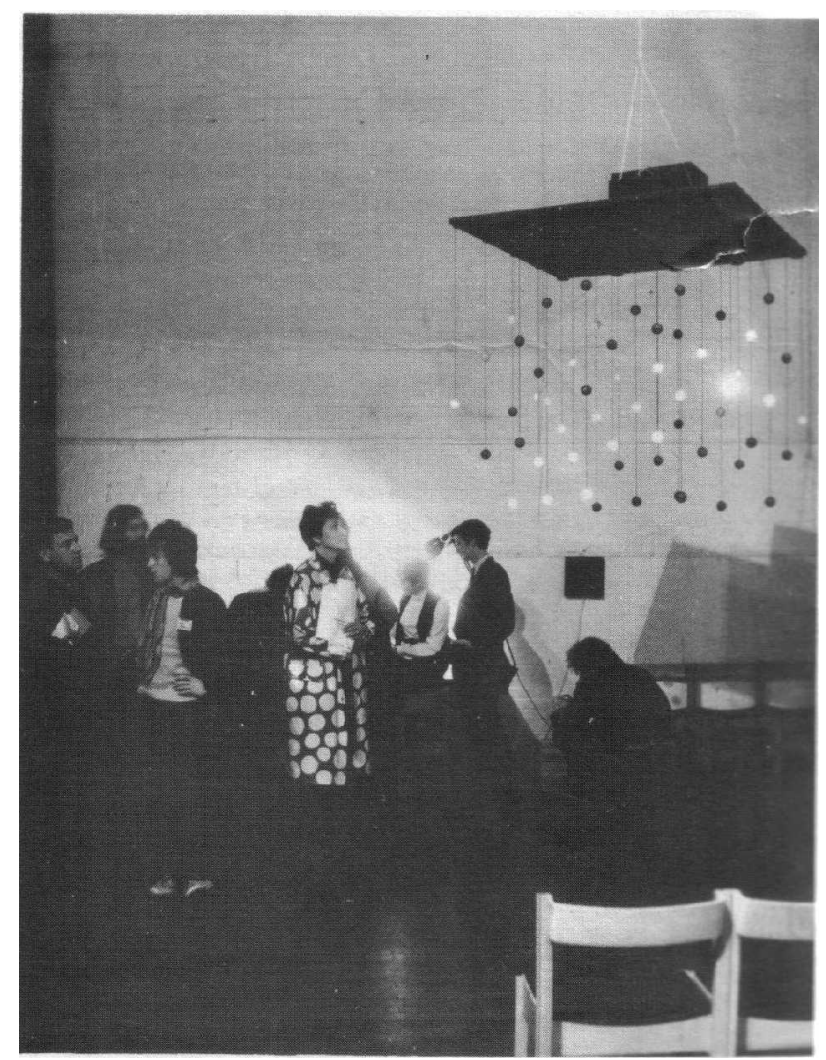

Figure 3. A rare photo of Event One showing part of the stage with exhibitors Adrian Nutbeem (left with hand on hip) and John Bucklow (far right crouching down).

Suspended work by Philip Hodgetts (upper right).

Photo by Peter Hunot, Courtesy of CAS

Adrian Nutbeem and John Bucklow (then third year students at Camberwell College of Arts) collaborated on an electronic performance art piece which integrated Bucklow's Folder, seen below and Nutbeem's Object-Text-Light-Interval. These two electronic devices allowed sound from the artists' own voices and other environmental sounds to be transformed into currents that activated a bank of seven lights. Photocells sensed both these lights and ambient light from the room. The signals triggered by the photocells were transformed by square-wave generators into sound which, by a controlled feedback, was re-inputted into the whole system. A flow diagram by Nutbeem, published in Studio International, illustrated how this work was programmed. Benthall reported that "The audio effect is of a low continuous sound punctuated by higher-pitched sounds [...] vibrating through one's whole nervous system and accompanied by the pulsing lights of variable brightness" [18]. 


\section{EVA 2009 London Conference 6-8 July \\ Catherine Mason}

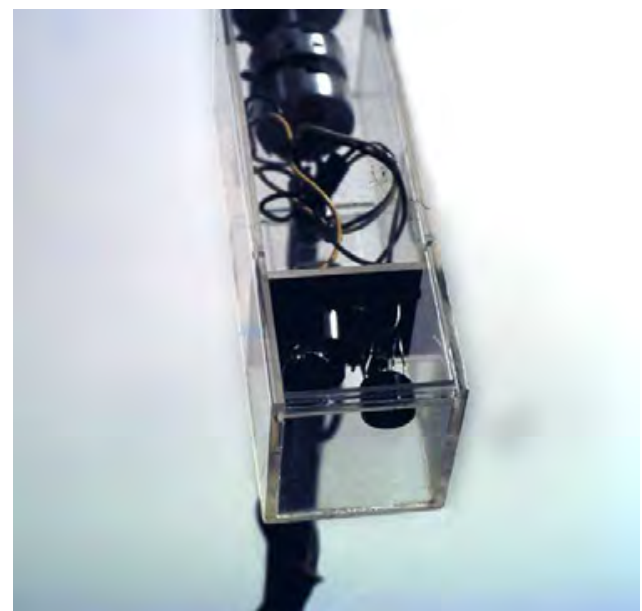

Figure 4. John Bucklow, The Folder (photo resistors coupled to flip-flop circuit with a square wave output), 1968 (c) The artist

Stroud Cornock, a Royal College of Art trained sculptor with an interest in Systems Theory, was concerned with participation and interaction in art. He exhibited plans, drawings and scale models for Gemini, an environmental work incorporating light and movement in two structures. In this he collaborated with Nick Nealson, an electronic engineer. Cornock saw the work's proposed urban site as an interactive, dynamic space with the ability to interact with people and relate to the inhabitants of that space. He believed the solution lay in devising a system which would respond to inputs and outputs, informed by feedback, rather than a static piece of traditional sculpture. This was art as process rather than object, an interactive art system informed by the principles of cybernetics designed, according to Cornock to "draw the viewer into a 'conversation'" [19].

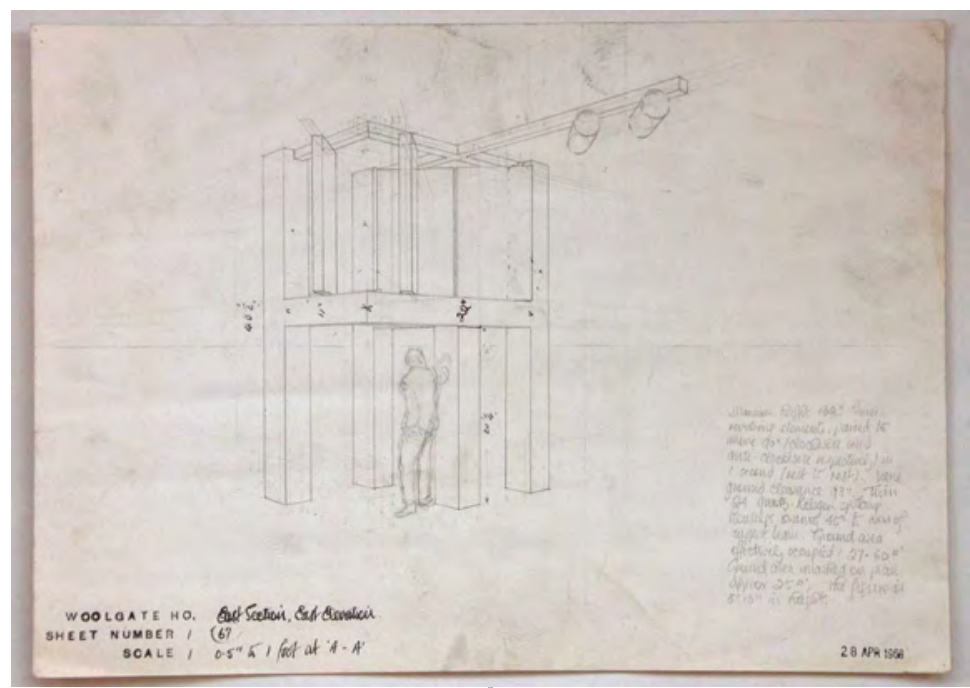

Figure 5. Stroud Cornock, Gemini System, April 1968 drawing of eastern structural element. (c) The artist 


\section{EVA 2009 London Conference 6-8 July \\ Catherine Mason}

Also on the sculpture front, Brower Hatcher, then in the post-diploma course at St Martins, exhibited what he describes as a 'kit of parts' which consisted of basic structural physical components made by the artist from pipe and tubing erected by him in the foyer throughout the weekend. The various components were constructed according to a computer-generated set of instructions, with programming assistance by Mallen. Peter Atkins of the St Martins sculpture department recommended him to Event One and suggested that he consider computing to drive his work that was based on chance and biomimetics. Of his exhibited work Hatcher recalled that "It was a performance on my part, assembling a construction of randomized parts. Structural issues were unresolved and it mostly spread along the floor" [20]. Hatcher went on to win the Sainsbury Sculpture Prize in 1970, before returning to his native America in 1972 and to this day uses computer progressions to create structures.

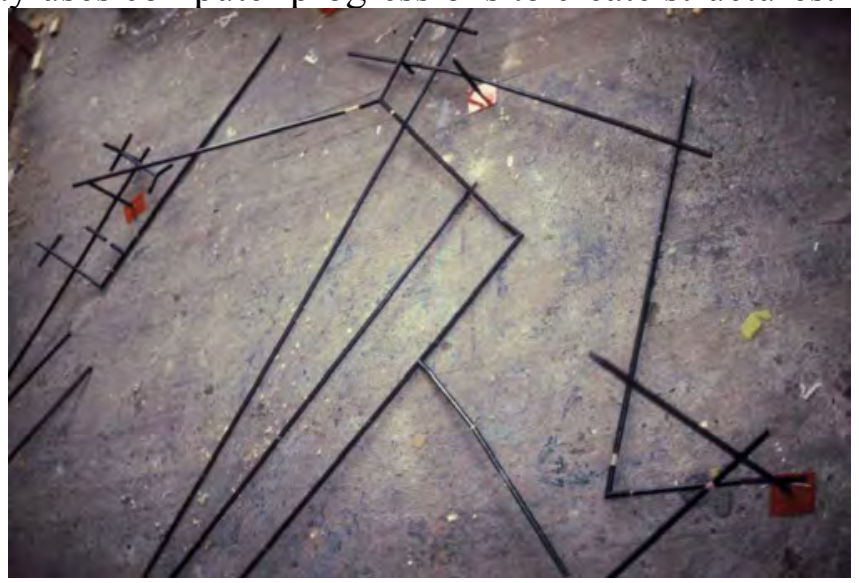

Figure 6. Brower Hatcher, installation of sculpture for Event One, 1969 Photo $\odot$ the artist

Films either made by computer or dealing with the subject were screened in the lecture theatre in daily sessions. These included Anthony Pritchett's The Flexipede (1967), the first fully surviving work of computer animation created in Britain. Unfortunately a complete list of films screened does not survive, but interestingly these were among the most controversial of exhibits eliciting either praise or derision in fairly equal measures from visitors (according to CAS questionnaires completed by visitors). Also on display were graphics by Bob Parslow from the computing department of Brunel University, who had, with Prof. Michael Pitteway, devised an early method of drawing on an Elliott 803 circa1966. Several American graphics were due to be exhibited but were held up in Customs, who seemed to believe that art made by machine was dutiable. This included Ken Knowlton and Leon Harmon's Studies in Perception (1966), a large plotter print of a nude constructed from the alphanumeric characters of an ASCII printer produced at Bell Telephone Laboratories (reported on the front page of the Evening News 29/03/69, 'Customs Seize Computer's Nude').

CAS engaged PR consultant Sydney Paulden to announce the formation of the society and to promote the forthcoming exhibition. Therefore press coverage of Event One was fairly broad with the major broadsheets and several tabloids as well as computing press reporting. Several reporters came from abroad. The novelty of the 
undertaking appears to have caught the press imagination. The Sunday Times called the use of computers to produces plays a 'dubious venture' (Sunday Times, 16/03/69). But The Observer believed Lansdown's ballet performance the 'highlight' of the show and printed a picture with an explanatory diagram ('Computer Calls the Dance', The Observer 30/03/69). Sutcliffe and Le Grice were interviewed on the BBC's radio programme Today (30/3/69) about the potential of computer drama. Benthall writing in Studio International (May and June 1969 issues) was the only art press coverage and he called for artists working with technology to be better resourced - a reminder of how costly it was to engage with emergent technologies back then.

The range of comments on the 129 surviving feedback questionnaires completed by visitors to the show demonstrate the difficultly in engaging with the general public when dealing not only with emergent technologies but also with a new type of art that was not recognised in the mainstream. As many visitors would have had no prior knowledge of computing, it is not surprising that most of the criticism centred on a lack of detailed information concerning exhibits, too few explanations and requests for more guidance and demonstrations. It was clear however that when a visitor was able to connect with an artist or exhibitor, it was a highly worthwhile experience. Several respondents scored the show high on informal contact with praise for the good interaction between disciplines. The largest complaint was poor acoustics and distracting noise from other exhibits in the hall making the talks (by Benthall and Gordon Pask) difficult to hear. Certainly the teletypes would have made a lot of noise. Three people compared it to Cybernetic Serendipity and pronounced Event One preferable, perhaps because of the informal workshop-like atmosphere where, if keen, a visitor had the opportunity to engage on quite a deep level.

\section{AFTER EVENT ONE}

A post-mortem session was held on 3 April at the British Computer Society London at which Metzger presented a paper Notes on the Crisis in Technological Art. In this he developed his argument for what he called "the most critical topic in technological artthe responsibility of the artist for his material and to society" [21] by delivering a plea for CAS to make a policy statement on the role of computers in war and the control of individual freedom. This served as a reminder to all concerned about the militaristic origins and possible abuse of technology. CAS took neither one stand or the other, rather attempted to reach a median allowing for co-operation between disciplines, access to expertise and equipment at the same time as encouraging personal expression, whilst attempting dissemination through exhibitions and events.

Following Event One, CAS continued to grow in strength and in the years that followed held a number of important exhibitions and conferences and its members continued to collaborate on numerous projects, art works and activities. There is room here to mention only two major ones. Due to its association with the computing world CAS was able to exhibit, hold demonstrations and performances at a number of computer industry trade shows. This, more than a decade in advance of the similar initiative of ACM SIGGRAPH in the United States. These included Computer Graphics '70 (also known as $C G$ '70) at Brunel University, Computer '70 at Olympia London and 
Datafairs '71 and '75. These tended to consist of displays of mostly wall-mounted computer graphics, as well as a programme of speakers. However for Computer '70 (September 1970), CAS produced the collaborative Ecogame, a simulation model of an economic system and the first multi-media interactive gaming system in the UK. The Ecogame was installed in the Science Museum, London in 1975 after touring to the first European Management Symposium in Davos Switzerland, making it the first and perhaps the fastest work of British digital art to enter a museum.

After Event One the next big CAS exhibition was Interact : Man, Society, Machine (1973), organised by CAS as a Fringe event at the Edinburgh Festival. Successful fundraising from the Scottish Arts Council allowed CAS to sponsor the production of four artworks: Edward Ihnatowicz's The Bandit, John Lifton's Green Music, Anna Valentina Murch's Tent and Stephen Willats's Edinburgh Social Model Construction Project. These were large-scale works and all except Lifton's were interactive and participatory in nature. They involved artists from strong fine art backgrounds and different networks from CAS and as such indicate the scope and ambition of CAS in engaging the wider art world and reaching different publics. None of these works could have existed without the computer. As Lansdown argued two years later using the work of Ihnatowicz, Lifton, Metzger and the Ecogame as examples, for the 'Proceduralists' (in which he counted himself) "... in computer art more than any other, the object is the process" [22].

\section{CONCLUSIONS}

Exhibitions such as Cybernetic Serendipity and Event One were facilitated and inspired by a post-war spirit of optimism in the (positive) power of new technologies. In fact, these were actually very avant-garde in their subject matter and manner of delivery, presenting a topic and style of artwork that was outside the mainstream of British art at this time. They represent a rare example of interdisciplinary collaboration within the history of modernism in Britain. As the only practitioner-led group specialising in creative applications of digital technologies, CAS was of vital importance for the continued development of this field in Britain. Obviously the CAS approach did not suit everyone, but the collaborative environment and inter-related networks which they facilitated during this period assisted practitioners with access to equipment and expertise, support, even occasional exhibition and funding opportunities, thus helping to mitigate some of the difficulty of production and dissemination experienced by early media artists. In the Event One catalogue there is an advertisement for Zinovieff's Electronic Music Studios in Putney and, on the back cover, an advert for the UNIVAC 1557/1558 Advanced Graphic Display System by Sperry Rand. These two adverts perhaps demonstrating a belief in how the two cultures could co-exist under one banner - that of CAS.

\section{ACKNOWLEDGEMENTS}

With thanks to George Mallen for suggesting this topic and to the EVA committee for the opportunity to present it. My continued grateful thanks for the unfailingly kind assistance provided by the artists and their families mentioned in this paper. 


\section{EVA 2009 London Conference 6-8 July \\ Catherine Mason}

\section{References}

[1] CAS. Promotion leaflet drafted by Alan Mayne. [undated c.1969]

[2] The CACHe project traced the inception, growth and development of British computer arts from its origins in the 1960s to the beginning of the 1980s. The findings of this research are published in MASON, C. A computer in the art room : the origins of British computer arts 1950-80. JJG, 2008. and in BROWN, P., GERE, C., LAMBERT, N. and MASON, C. (Editors) White heat cold logic : British computer art 1960-1980. MIT Press, 2008.

[3] as note 1.

[4] CAS was re-formed in 2004 and $P A G E$ is being regularly published again, see: http://www.computer-arts-society.org/

[5] METZGER, G. First Manifesto. 1961.

[6] LE GRICE, M. Never the same again In : White heat cold logic : British computer art 1960-1980. MIT Press 2008. pp.219-228.

[7] BOREHAM, D. interview with author, 26/05/05

[8] BENTHALL, J. Technology and art 3. Studio International, May 1969, p.212.

[9] METZGER G. PAGE 1, 1969.

[10] as note 8 .

[11] MALLEN, G. communication with author, 11/05/09

[12] CAS. Event One catalogue 1969 (no page numbers)

[13] as note 12.

[14] SUTCLIFFE, A. PAGE 63, June 2007.

[15] LANSDOWN, R. J. Computer art for theatrical performance. [unpublished (?) paper] Lansdown archive, Middlesex University.

[16] LIFTON quoted in BENTHALL, J. Science and technology in art today. London : Thames \& Hudson, 1972. p.74.

[17] John Lifton Green Music. [Exhibition leaflet] London : Whitechapel ArtGallery, Experimental Gallery, 1975.

[18] BENTHALL, J. Technology and art 4. Studio International, June 1969, p.260.

[19] CORNOCK, S. interviews and communication with author 20/04/09.

[20] HATCHER, B. communication with author 29/04/09.

[21] METZGER, G. copy of reprinted 'Automata in History' from Studio International, March 1969, p.107, with typed note on bottom of page. Copies of this were distributed at Event One.

[22] LANSDOWN, R. J. PAGE 19, December 1971. 